\title{
Cost-effectiveness analysis of nonoperative management versus open and laparoscopic surgery for uncomplicated acute appendicitis in Colombia
}

\author{
César Augusto Guevara-Cuellar ${ }^{*}$, María Paula Rengifo-Mosquera and Elizabeth Parody-Rúa
}

\begin{abstract}
Background: Traditionally, uncomplicated acute appendicitis (AA) has been treated with appendectomy. However, the surgical alternatives might carry out significant complications, impaired quality of life, and higher costs than nonoperative treatment. Consequently, it is necessary to evaluate the different therapeutic alternatives' cost-effectiveness in patients diagnosed with uncomplicated appendicitis.

Methods: We performed a model-based cost-effectiveness analysis comparing nonoperative management (NOM) with open appendectomy $(\mathrm{OA})$ and laparoscopic appendectomy $(L A)$ in patients otherwise healthy adults aged 18-60 years with a diagnosis of uncomplicated AA from the payer's perspective at the secondary and tertiary health care level. The time horizon was 5 years. A discount rate of $5 \%$ was applied to both costs and outcomes. The health outcomes were quality-adjusted life years (QALYs). Costs were identified, quantified, and valorized from a payer perspective; therefore, only direct health costs were included. An incremental analysis was estimated to determine the incremental cost-effectiveness ratio (ICER). In addition, the net monetary benefit (NMB) was calculated for each alternative using a willingness to pay lower than one gross domestic product. A deterministic and probabilistic sensitivity analysis was performed.
\end{abstract}

Methods: We performed a model-based cost-effectiveness analysis comparing nonoperative management (NOM) with open appendectomy $(\mathrm{OA})$ and laparoscopic appendectomy (LA) in patients otherwise healthy adults aged 18-60 years with a diagnosis of uncomplicated AA from the payer's perspective at the secondary and tertiary health care level. The time horizon was five years. A discount rate of $5 \%$ was applied to both costs and outcomes. The health outcomes were quality-adjusted life years (QALYs). Costs were identified, quantified, and valorized from a payer perspective; therefore, only direct health costs were included. An incremental analysis was estimated to determine the incremental cost-effectiveness ratio (ICER). In addition, the net monetary benefit (NMB) was calculated for each alternative using a willingness to pay lower than one gross domestic product. A deterministic and probabilistic sensitivity analysis was performed.

Results: LA presents a lower cost $(\$ 363 \pm 35)$ than OA ( $\$ 384 \pm 41)$ and NOM ( $\$ 392 \pm 44)$. NOM exhibited higher QALYS (3.3332 \pm 0.0276$)$ in contrast with LA (3.3310 \pm 0.057$)$ and OA (3.3261 \pm 0.0707$)$. LA dominated the OA. The ICER between LA and NOM was $\$ 24,000 / Q A L Y$. LA has a $52 \%$ probability of generating the highest NMB versus its

*Correspondence: cguevara@icesi.edu.co

Faculty of Health Sciences, Universidad Icesi, Calle 18 No. 122-135 Pance,

70000 Cali, Colombia

c) The Author(s) 2021. This article is licensed under a Creative Commons Attribution 4.0 International License, which permits use, sharing, adaptation, distribution and reproduction in any medium or format, as long as you give appropriate credit to the original author(s) and the source, provide a link to the Creative Commons licence, and indicate if changes were made. The images or other third party material in this article are included in the article's Creative Commons licence, unless indicated otherwise in a credit line to the material. If material is not included in the article's Creative Commons licence and your intended use is not permitted by statutory regulation or exceeds the permitted use, you will need to obtain permission directly from the copyright holder. To view a copy of this licence, visit http://creativeco mmons.org/licenses/by/4.0/. The Creative Commons Public Domain Dedication waiver (http://creativecommons.org/publicdomain/ zero/1.0/) applies to the data made available in this article, unless otherwise stated in a credit line to the data. 
counterparts, followed by NOM (30\%) and OA (18\%). There is a probability of 0.69 that laparoscopy generates more significant benefit than medical management. The mean value of that incremental NMB would be $\$ 93.7$ per patient.

Conclusions: LA is a cost-effectiveness alternative in the management of patients with uncomplicated AA. Besides, LA has a high probability of producing more significant monetary benefits than NOM and OA from the payer's perspective in the Colombian health system.

Keywords: Cost-effectiveness, Nonoperative management, Open appendectomy, Laparoscopic appendectomy, Acute appendicitis

\section{Background}

Acute appendicitis (AA) is one of the most common causes of abdominal pain. The European Association for Endoscopic Surgery estimates this condition affects from 5.7 to 57 per 100,000 people each year. The lifetime risk is about $16.3 \%$ in industrialized countries [1], $8.6 \%$ for men, and $6.7 \%$ for women in developing countries [2]. Furthermore, the total medical costs associated with this condition oscillate between $\$ 5989$ and $\$ 6075$ per patient in developing countries $[3,4]$. In Colombia, it is estimated that the cumulative costs generated by open (OA) and laparoscopic appendectomy (LA) are US\$65,753 and $\$ 66,425$, respectively, in 2013. Finally, complications can generate cumulative costs of approximately $\$ 297$ for OA and $\$ 271$ for LA in that period [5]. Despite being a benign condition, its high incidence and risk of complications represent a significant financial burden for healthcare systems.

Traditionally, AA has been treated surgically. The surgical approach has been preferred because of the high success rate, eradication of the underlying cause, and the relatively low procedure's complexity [6]. Indeed, around 300,000 appendectomies are performed annually only in the United States, preferring the LA [7]. However, the technological restrictions, the cost of some supplies, and the lack of trained staff are barriers to LA's wider adoption [8, 9]. For this reason, a significant proportion of appendectomies are still performed through an open approach worldwide $[5,10]$. An example of this is a recent study in Bogota, Colombia, where 65,625 subjects underwent appendectomy between 2013 and 2015. Of these, $92.9 \%$ underwent $\mathrm{OA}$, and only $7.1 \%$ underwent LA [2]. Nevertheless, OA presents a higher risk of complications such as infection of the surgical site, incisional hernias, abdominal pain, and obstructive symptoms [11].

In addition to the above, some situations have questioned traditional surgical management and propose alternative therapeutic approaches. Firstly, there are concerns about the safety of surgical treatment in highrisk surgical patients. Secondly, recent studies suggest that uncomplicated AA may be a condition with a high likelihood of spontaneous remission with supportive care alone [12]. Finally, several well-designed controlled clinical studies have shown the potential benefits of nonoperative management (NOM). The most recent long-term Appendicitis Accuta Trial (APPAC) compared antibiotic versus surgical management. In this study, NOM presented a success rate of $72.7 \%$ within 5 years [13]. Additionally, several systematic reviews have reported clinical benefits of NOM versus surgical approach $[1,6,14-21]$.

A review of the literature shows that NOM brings certain advantages over appendectomy. These advantages include a significantly lower overall complication rate in the short term, a reduction of approximately $50 \%$ or more in costs, and a lower disability than surgery [3]. Additionally, there are other variables in which no statistically significant difference has been found between the two alternatives, such as hospital stay length [11,22]. However, NOM has disadvantages, such as a significant probability of evolution to complicated appendicitis and recurrence, leading to incurring cost overruns.

This dilemma requires evaluating the long-term impact and economic implications of NOM of uncomplicated AA. Although cost-effectiveness analyses for this condition have been carried out in developed and developing countries, almost all evaluated NOM versus LA only [3-5, 23-25]. OA's exclusion in these evaluations might not represent the daily clinical practice in many developing countries where this approach is routine [10]. In this sense, our study seeks to evaluate the three alternatives simultaneously.

This study's objective was to evaluate the cost-effectiveness of NOM compared to OA and LA in patients diagnosed with uncomplicated AA in the Colombian health system.

\section{Methods \\ Statements}

A model-based cost-effectiveness analysis was conducted for estimating the efficiency of OA, LA, and NOM in the treatment of uncomplicated AA from the perspective of the public payer in the Colombian Health System. The Colombian health system is based on a market mechanism regulated by the Ministry of Health. There are public and private entities responsible for the insurance 
and provision of health services. The primary sources of financing are the quotations of employees and employers, who finance the private contributory regime, and fiscal resources obtained through general taxes, which finance the public subsidized regime. We refer the reader to the corresponding literature for more details on the Colombian health care system $[26,27]$.

The national methodological guideline for economic evaluation was followed [28]. This guideline recommends QALYs to measure health outcomes, adopt a discount rate for costs and outcomes similar to that adopted by countries in the region (3-5\%), and a cost-effectiveness threshold of less than one Gross Domestic Product (GDP) per capita.

\section{Design and structure of the model}

A literature review was conducted to identify published model-based economic evaluations. Although four models were found, no one was employed in our economic evaluation because they evaluated complicated appendicitis, prophylactic appendectomy, and different length of hospital stay giving antibiotic therapy $[4,23,29,30]$. For this reason, a de novo decision model was designed.

The model evaluated three therapeutic alternatives for uncomplicated AA. Two options are surgical (OA and LA), which include short-term postoperative complications. The criteria for defining the realization of OA or LA are those reported in the POSAW study $[6,10]$. OA must be performed in those hospitals where laparoscopic equipment or surgeons trained in laparoscopy are not available. Additionally, the surgeon may decide to perform OA because of the perception that this alternative has shorter operative and anesthetic times or lower risk of intra-abdominal abscess [13, 31]. Short-term postoperative complications included in the model were operative site infection, intra-abdominal abscess, and ileus [13]. Long-term complications (e.g., incisional hernias or fistulas) and death were not included in the model because of their low probability of occurrence in patients with uncomplicated AA [13, 31].

The third alternative is NOM, which aims to reduce inflammation with the administration of antibiotics and other non-surgical interventions (e.g., analgesics, intravenous fluids). The absence of clinical improvement or absence of improvement in the diagnostic aids leads to realizing an appendectomy. The clinical improvement allows the patient to remain with the appendix. However, this permanence generates a risk of long-term recurrences or develops to complicated AA (i.e., presence of phlegmon, abscess or mass). For this reason, the model also included medical management (i.e. antibiotics plus percutaneous drainage) followed by the interval appendectomy in this case. However, the initial surgical management without medical treatment of complicated appendicitis also was considered. The inclusion of the two alternatives for managing complicated AA is because there is controversy about performing interval appendectomy in patients with complicated AA [32-34]. A decision tree was considered appropriate for modeling because events in uncomplicated AA usually have a short duration and rapid resolution. Figure 1 displays the model structure.

The model's assumptions were as follows: (I) The management of intra-abdominal abscess was the same regardless of the type of surgery. (II) Death was not included because it has a very low probability $(<1 \%)[13]$. (III) The incisional hernia and the enteric fistula were not considered because they are negligible for both surgical procedures (0.4\% and 0.5\%) [35]. (IV) Abdominal sepsis was not included because of its very low incidence in uncomplicated AA [36]. (V) Postoperative ileus is managed within the same hospitalization without considerably affecting the quality of life.

The model was tested for face and external validation. For face validity, the structure of the model was designed based on updated clinical practice guidelines and protocols. Subsequently, the structure was repeatedly reviewed with a surgeon who approved the different courses of action of the tree. These courses of action had to represent the usual clinical practice in Colombia. For external validation, critical parameters of the model were selected: incidence of complications for OA and LA; recurrence of appendicitis at five years in patients who underwent NOM, and probability of complicated appendicitis in case of recurrence. The $95 \%$ confidence interval was calculated for each parameter. Calibration was not performed if there was overlap between the model and study confidence intervals. The results of the external validation are shown in Additional file 1: Table S1.

\section{Population, setting, subgroups and alternatives}

The hypothetic population evaluated by our model included otherwise healthy adults aged 18 years to 60 years with a diagnosis of uncomplicated AA. Uncomplicated AA was defined as the absence of clinical signs suggestive of peritonitis and no evidence of inflammatory mass, phlegmon, abscess, or appendicolith in abdominal imaging. A subgroup analysis in older patients was not conducted because of a lack of long-term clinical data for patients older than 60 years. The context of the evaluation is the secondary and tertiary levels of the public health care system.

The alternatives included surgical and medical options. The surgical procedures evaluated were OA and LA. The NOM includes clinical observation in the hospital for at least $72 \mathrm{~h}$, assessment by a surgeon, routine diagnostic 


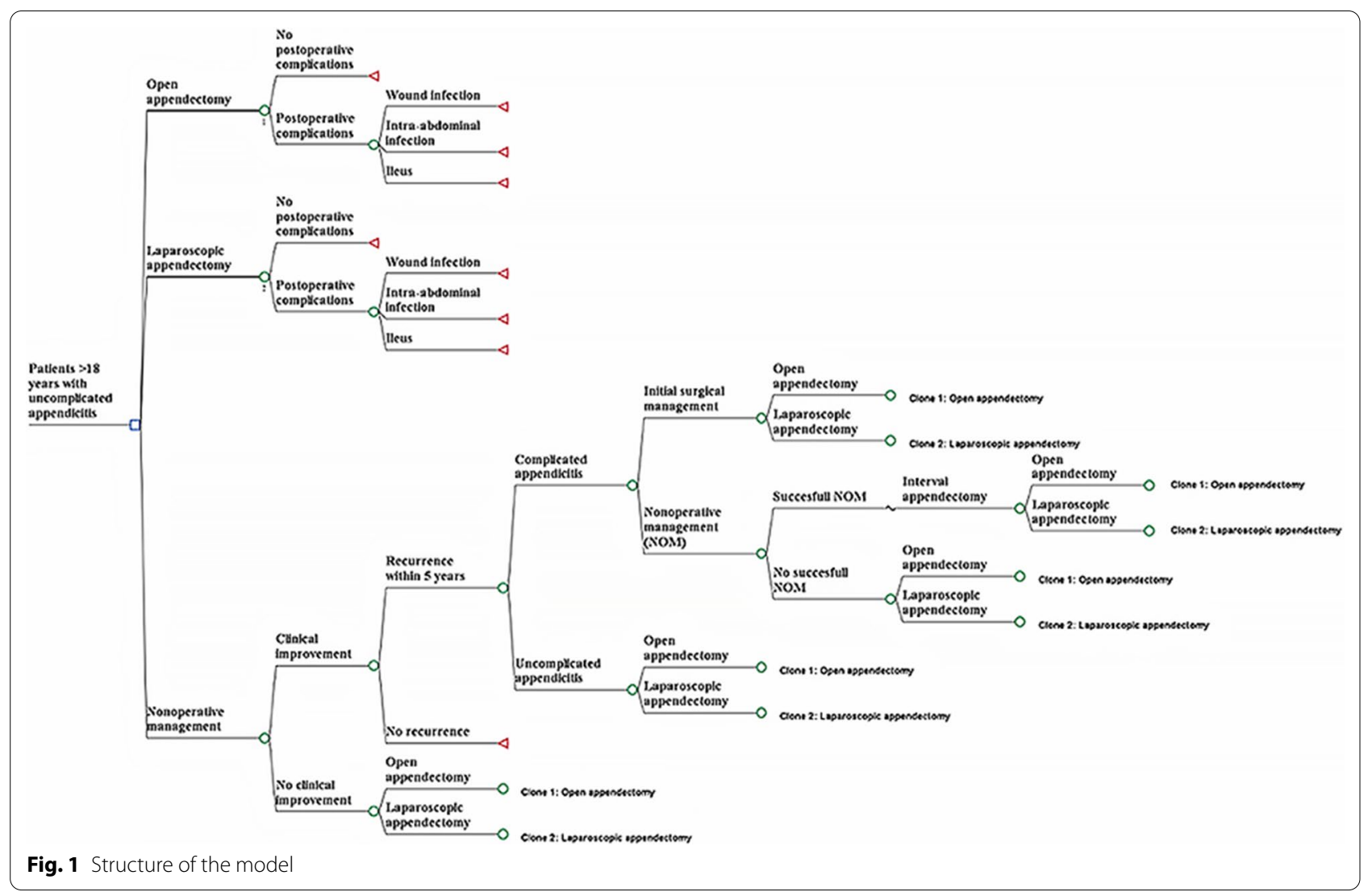

aids, and antibiotics administration. The antibiotics regimen evaluated included ertapenem (1gr c/24 $\mathrm{h} \times 3$ days), levofloxacin $(500 \mathrm{mg} \mathrm{c} / 24 \mathrm{~h} \times 7$ days $)+$ metronidazole (500 $\mathrm{mg} \mathrm{c} / 8 \mathrm{~h} \times 7$ days). These alternatives were extracted from clinical literature [11]. Besides, expert surgeons validated that those represent the routine clinical practice in our context. Other antibiotic regimens were not evaluated due to the absence of long-term clinical data.

\section{Model inputs}

Costs were identified, quantified, and valorized from a payer perspective; therefore, only direct health costs were included.

Direct costs are valued by tariffs regulated by the Ministry of Health and are considered acceptable proxies for the production costs of health services. The most commonly used tariff for valuing health services (i.e., diagnostic and therapeutical procedures) is the Manual Tarifario ISS [37]. Some health services are valued as a package of services and others on a per-event basis. The payer and the provider agree on a value for a predetermined set of services in a package. Services not included must be valued and paid for additionally. In pay-per-event, each service is priced independently, and the total cost is the sum of the individual costs of each service. The unitary costs for medications were obtained from the Sistema de Informacion de Medicamentos [38].

According to the tariff, OA and LA are valued as a package. The package for OA includes pre-surgical evaluation by the surgeon and anesthesiologist, performance of the procedure, post-surgical controls, operating room fees, surgical supplies (e.g., gauze, compresses, disposable clothing), and post-surgical hospitalization days. Postsurgical complications are not included in the package.

The value of the package for LA is the same value for OA, but the value of the single disposable trocar is added.

The NOM and complications are not valued as a package but as an event. For this reason, each resource used is valued independently, and the total cost will depend on the number of resources consumed. The identification and quantification of resources were obtained from the clinical practice guidelines and from an expert who validated them [6].

The resources quantified and valued for NOM included hospitalization, evaluation by a surgeon, fluids, analgesics, diagnostic aids (C-reactive protein, hemogram), and antibiotics (i.e., ertapenem, levofloxacin, and metronidazole).

In wound infection, antibiotics (i.e., cephalexin), medical evaluation, and analgesic were valued. For intra-abdominal 
infection and complicated AA, the resources valued were hospitalization, percutaneous drainage guided by ultrasound, antibiotics (i.e., ceftriaxone plus metronidazole), diagnostic aids, and evaluation by a surgeon. Finally, the resources valued in ileus were hospitalization, fluids, analgesics, diagnostic aids, and nasogastric tube placement.

Total cost was calculated by multiplying the unit cost by the units required of each resource. The costs were expressed US dollars at the current exchange rate in January 2021, reported by the Central Bank of Colombia (1 $\mathrm{USD}=\mathrm{COP} 3478$ ) [39]. Following Colombia's methodological guide for economic evaluations, all costs were adjusted by $30 \%$ for inflation [28].

The resources used in each alternative are shown in Additional file 2: Table S2.

The health outcomes were quality-adjusted life years (QALYs) according to the methodological guidelines. Given the absence of utility and disutility data for the health states in our country, the utility weights were extracted from the Cost-Effectiveness Analysis Registry of the Tufts Medical Center [40]. The QALYs were obtained by multiplying each event/state's utility by the length of time expressed in years.

The utilities used in each event are shown in Additional file 3: Table S3.

The time horizon was five years. This horizon was chosen because some late complications can occur during this period in patients managed with NOM [13]. A discount rate of $5 \%$ was applied to both costs and outcomes. This rate is recommended for the methodological guidelines for economic evaluation in Colombia [28].

The probabilities of each of the complications for OA were obtained from systematic reviews [14-16, 18, 20, 21, $36,41-43]$. The probabilities of LA complications were calculated by multiplying the probability of OA complication by the relative risk obtained from meta-analyses [14-16, $18,20,21,36,41-43]$. The probabilities of clinical improvement, recurrence, and complicated appendicitis with NOM were obtained from the Salminen et al. [13]. The probabilities of selecting open or laparoscopic appendectomy or medical or surgical management of complicated appendicitis were obtained from observational studies [10, 31, 44-47].

\section{Incremental analysis}

An incremental analysis was estimated to determine the incremental cost-effectiveness ratio (ICER).

This ratio is expressed mathematically in the following expression:

$$
I C E R=\frac{\text { Incremental cost }_{\text {Incremental } Q A L Y S}}{\text { InALY } B-Q A L Y_{A}}
$$

In addition, the net monetary benefit (NMB) was calculated for each alternative. This benefit is mathematically expressed as follows:

$$
N M B=\Delta E \lambda-\Delta C
$$

$\Delta \mathrm{E}$ indicates the incremental effect (i.e., the difference of QALYs between two alternatives), $\Delta C$ indicates the incremental cost, and $\lambda$ means the willingness to pay. The York Health Economic Consortium defines the NMB as "...a summary statistic that represents the value of an intervention in monetary terms when a willingness to pay threshold for a unit of benefit is known." [48].

The willingness to pay threshold was $\$ 6667$. This threshold is equivalent to 1 GDP per capita in Colombia. The Colombian methodological guide for economic evaluations established this threshold to consider a technology highly cost-effective following the recommendations of the World Health Organization [28, 49, 50].

\section{Uncertainty analysis}

A deterministic and probabilistic sensitivity analysis was performed. The deterministic analysis was a one-way sensitivity analysis whose objective was to identify which input affects the ICER. The results were graphed in a tornado plot for the essential variables. If the input is modifiable, a threshold analysis was performed to identify the value at which a non-cost effective alternative could become cost-effective.

The stochastic and parameter uncertainties were evaluated through the first- and second-order Monte Carlo simulations. A first-order microsimulation was performed with 1000 trials for each alternative to evaluate stochastic uncertainty (i.e., random variability in outcomes between identical patients). For this purpose, random utility values were assigned to each trial when entering the model. The parameter uncertainty was evaluated with a second-order Monte Carlo simulation with 10,000 iterations. A beta-distribution represents the uncertainty in utility and probability because these are binomial parameters constricted in the interval from zero to one. A Dirichlet distribution, a multivariant generalization of beta distribution, was used to model polytomous events (e.g., short-term complications in surgical alternatives). The Poisson distribution was used to model the number of resources. Resource values were modeled using a uniform distribution. Unfortunately, the resource values in the national tariffs are reported as a single value, with no mean or standard deviation to support the use of gamma or log-normal distribution to model this parameter. The relative risks were modeled using a uniform distribution, where lower and upper values correspond to the $95 \%$ confidence interval reported in the meta-analysis. The distribution parameters are presented 


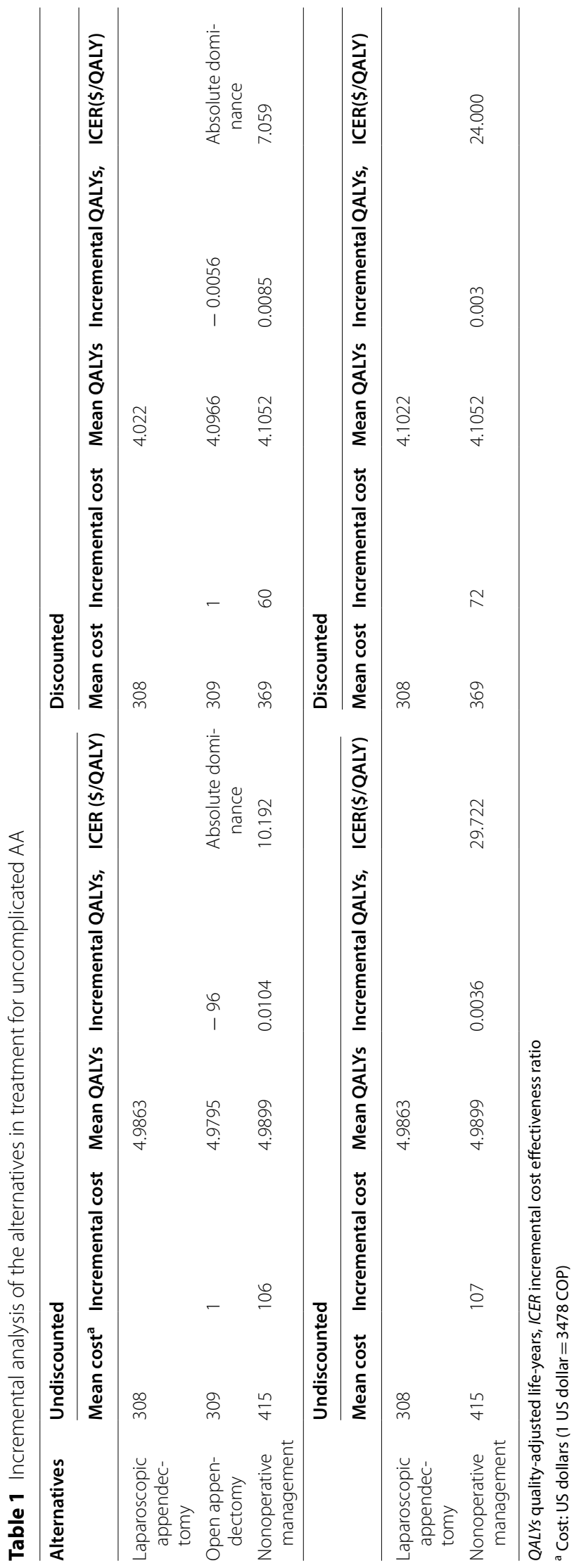


in Additional file 4: Table S4. Finally, a simulation with 100,000 trials was performed to evaluate the effects on incremental cost in a hypothetical population with this number of patients.

The model was evaluated with TreeAge Health Pro 2020 software (TreeAge Software, Inc., USA).

This study did not require ethical approval because there was no participation of humans or animals.

\section{Results}

The deterministic incremental analysis is presented in Table 1. This analysis revealed that LA dominates OA. Contrastingly, the NOM produced 0.003 more QALYs per patient (discounted) than LA but at a higher discounted incremental cost (\$61 per patient). The ICER of $\$ 24,000 / \mathrm{Q} A L Y$ additional is above the willingness to pay 1GDP per capita in Colombia (\$6667/QALY additional). Therefore, NOM would not be considered an efficient alternative for that willingness to pay.

The deterministic sensitivity analysis revealed that NMB is influenced by the cost of LA, NOM, and hospitalization time in LA. It is observed that when the costs of LA range between $\$ 150$ and 350, the NMB ranges between $\$ 27,153$ and $\$ 26,910$. Similarly, the analysis shows that a decrease in LA hospitalization time by two days could increase the NMB by only $0.05 \%$ (from $\$ 27,041$ to $\$ 27,055)$. Finally, the reduction of medical management costs by $\$ 200$ produces an increase in NMB from $\$ 26,908$ to $\$ 27,108$. The tornado graph and the threshold analysis are available in the (Addditional file 5: Figures S1-S3). These results show that the reduction in costs of LA could generate the most significant variability in NMB.

Table 2 presents the results of the probabilistic sensitivity analysis. The Monte Carlo simulation reveals that LA presents a lower cost $(\$ 363 \pm 35)$ than OA $(\$ 384 \pm 41)$ and NOM $(\$ 392 \pm 44)$. On the other hand, NOM exhibited higher QALYs $(3.3332 \pm 0.0276)$ in contrast with LA $(3.3310 \pm 0.057)$ and OA (3.3261 \pm 0.0707$)$. Histograms for each of these variables can be found in Addditional file 5: Figures S4-S20.

The higher efficiency of LA was consistent when incorporating uncertainty into the model. The acceptability curve in Fig. 2 plots the proportion of iterations in which each alternative had the greater NMB for different willingness-to-pay. This graphic shows that LA has a $52 \%$ probability of generating the highest $\mathrm{NMB}$ versus its counterparts, followed by NOM (30\%) and OA (18\%). The choice of LA is not modified by greater or lesser willingness to pay or resource availability.

Figure 3 sets out the incremental NMB between LA and NOM (i.e., the subtraction of the NMB of the two alternatives) for a willingness to pay 1 GDP per capita.
This graph shows a probability of 0.69 that laparoscopy generates more significant benefit than medical management. The mean value of that incremental NMB would be $\$ 93.7$ per patient. That mean value increases to $\$ 180$ if the willingness to pay increases to 3 GDP per capita. See Addditional file 5: Figure S21.

Simulation results with 100,000 trials produced costs of $\$ 36,220,164( \pm 3,422,719)$ with LA, $\$ 38,374,539$ $( \pm 4,030,340)$ with $\mathrm{OA}$, and $\$ 38,194,731( \pm 4,451,123)$ with NOM. Thus, performing OA and NOM instead of LA results in over expenditures on average of $\$ 2,154,375$ and $1,974,567$ per 100,000 patients. Histograms are in Addditional file 5: Figures S1-S8.

\section{Discussion}

Our study results show that LA has a high probability of producing higher $\mathrm{NMB}$ than $\mathrm{OA}$ and NOM in patients with uncomplicated AA with a willingness to pay less than 1 GDP capita.

The lower cost of LA could explain this higher benefit. Previous studies have shown that LA might have lower costs than the open approach. These studies suggest that the reduced cost is explained by the shorter length of hospital stay, quicker postoperative recovery, and the lower probability of postoperative complications $[5,24$, 51-53]. In this sense, the results of our model are consistent with those reported in the literature.

Likewise, our model revealed that the costs of LA are lower than NOM. This result differs from other published economic evaluations, which have demonstrated that NOM is cost-saving compared to surgical alternatives. This difference could be explained by the different time horizons of these studies. Sippola et al. followed some participants in the APPAC study for 1 year [3]. On the other hand, Wu et al. designed a decision model with a 1-year time horizon [23]. By adopting a shorter time horizon, the costs of patients who will recur after the first year would not be estimated. Salminen et al. demonstrated that the percentage of people who underwent appendectomy could increase from 27 to $40 \%$ after the first year [13]. Of these patients, almost $10 \%$ might recur with complicated appendicitis, which implies higher costs subsequently. Sceats et al. revealed that NOM was associated with higher abscess rates, readmission, and higher overall care costs [54]. As long as the appendix remains, the risk of recurrence is latent.

LA might represent significant savings for the health care system. Our model estimated a mean value of more than 2 million savings for every 100,000 LA performed instead of $\mathrm{OA}$ and more than 1 million compared to NOM. The probability of achieving these savings might be greater than $64 \%$. This saving would represent $2.3 \%$ and $1.4 \%$ respectively of the total health expenditure for 
Table 2 Results of probabilistic sensitivity analysis

\begin{tabular}{llll}
\hline & $\begin{array}{l}\text { Open } \\
\text { appendectomy }\end{array}$ & $\begin{array}{l}\text { Laparoscopic } \\
\text { appendectomy }\end{array}$ & $\begin{array}{l}\text { Nonoperative } \\
\text { management }\end{array}$ \\
\hline Cost $^{\mathrm{a}}$ (USD\$) & & & \\
Mean & 384 & 363 & 392 \\
Std Deviation & 41 & 35 & 44 \\
Minimum & 295 & 295 & 264 \\
Median & 377 & 359 & 389 \\
Maximum & 573 & 359 & 635 \\
QALYS & & & \\
Mean & 3,3261 & 3,3310 & 3,3332 \\
Std Deviation & 0,0707 & 0,0570 & 0,0276 \\
Minimum & 2,3643 & 2,4987 & 2,8988 \\
Median & 3,3417 & 3,3417 & 3,3417 \\
Maximum & 3,3417 & 3,3417 & 3,3417 \\
\hline
\end{tabular}

QALYs quality-adjusted life-years

${ }^{\text {a }}$ Cost: US dollars ( 1 US dollar $=3478$ COP)

many people in Colombia [55]. From a financial perspective, LA might be the best option for the overall health care system, especially the secondary and third care level.

A meaningful reduction in the cost of the NOM could become a more efficient alternative than LA. According to our model, this objective would be attained by reducing NOM costs by $55 \%$. In this case, the main expense was represented by the antibiotic regimen. Potentially, the use of other lower-cost antibiotic regimens might improve efficiency. Unfortunately, the lack of long-term comparative studies of antibiotic regimens is a limitation.
On the other hand, NOM provided a minimal increase in QALYs than the surgical alternatives. Our model revealed that NOM provided 0.003 and 0.0086 QALYs more than LA and OA, respectively. That marginal health benefit is equivalent to having 1 and 3.1 days in perfect health compared to LA and OA. Among the factors that could explain these differences are the lower probability of adverse events, less pain, and shorter absence from work than surgical options. In addition to a significant proportion who do not present symptoms or recurrence [42]. Another reason is the surgery could affect the quality of life for up to a month after being carried out [56].

Despite the above results, NOM of uncomplicated appendicitis might represent an efficient alternative in some situations. The first situation would be in case of lack of surgeons in some regions. In this case, the additional costs of transporting the patient to a center would result in LA not being the most efficient alternative. Also, the delay in the treatment would increase the risk of complications. The second situation is when the only option available is OA. This situation is frequent in hospitals where there is neither the technology nor the surgeons trained to perform LA. Two other possible situations would be in patients with high surgical risk or a collapse of the health system due to extreme public health situations (e.g., COVID). However, these two situations were not evaluated by our model.

Our economic evaluation has several limitations. Firstly, we considered a time horizon of 5 years only. This consideration might underestimate costs or overestimate QALYs in NOM because subsequent events

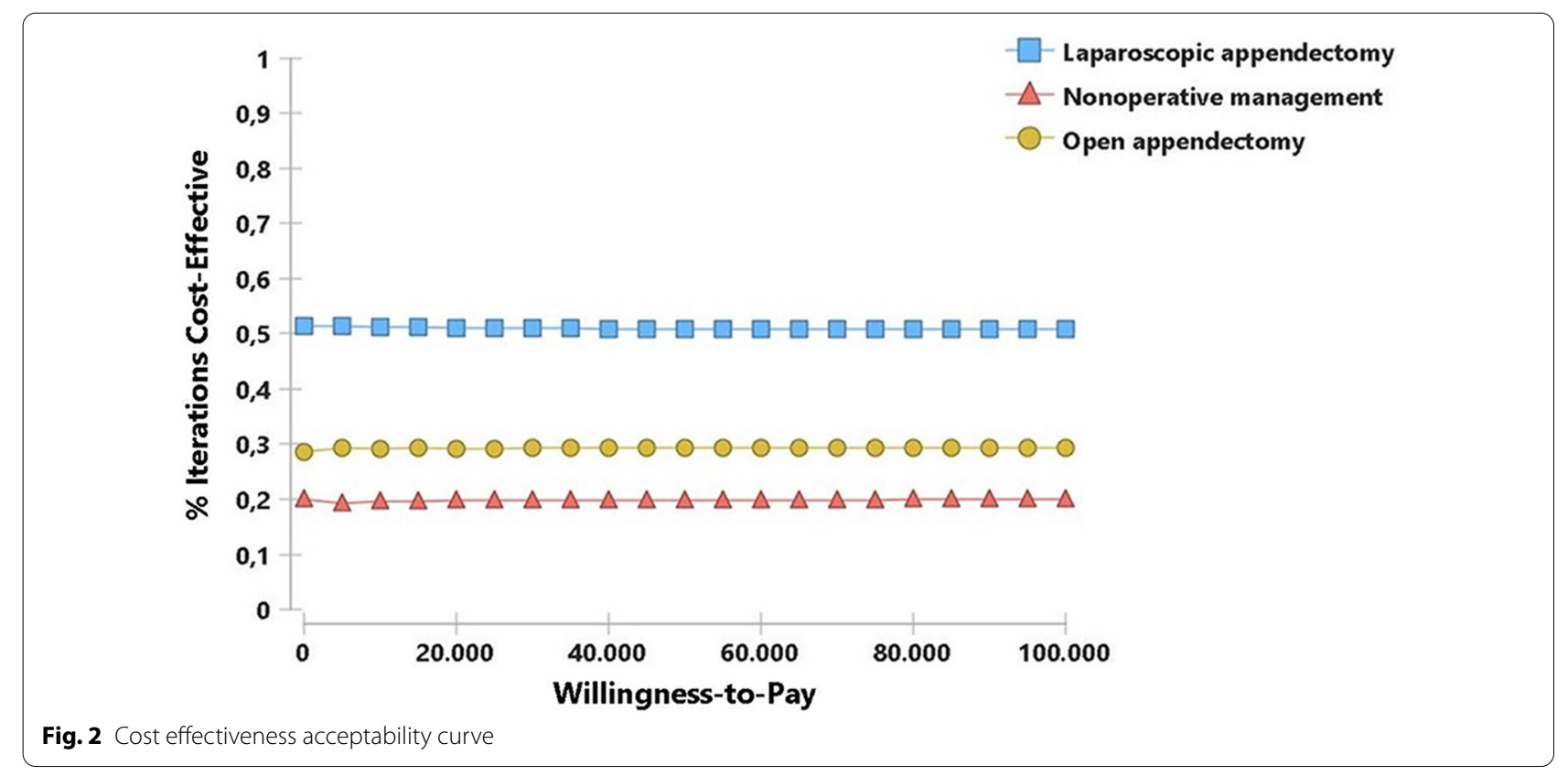




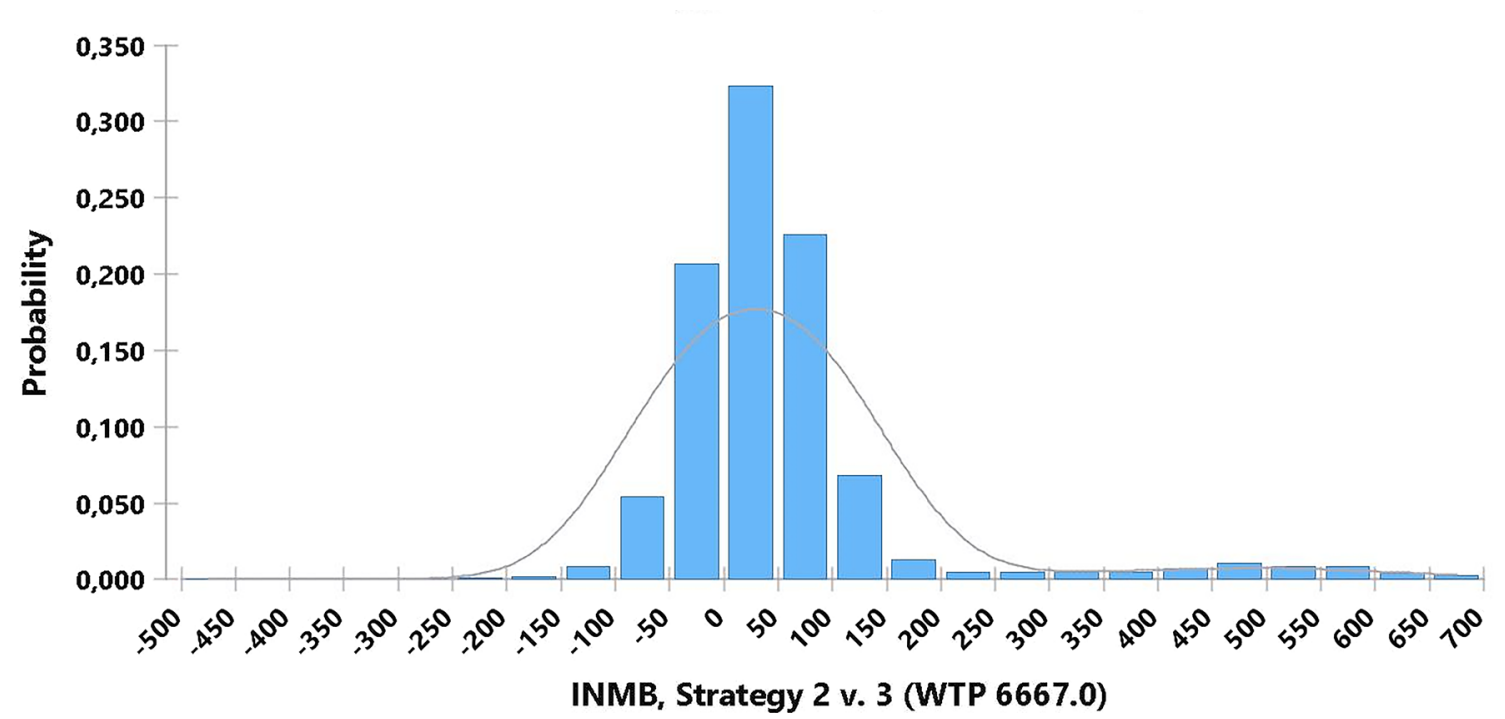

Fig. 3 Distribution of incremental net monetary benefit laparoscopy vs medical treatment

are not quantified. Nevertheless, the incidence of this disease tends to decrease in the older population [57, 58]. Secondly, our evaluation did not include an analysis by the patients' subgroup. Possibly, NOM may be a more efficient alternative in patients with high surgical risk (e.g., older patients). To incorporate heterogeneity in baseline health states, we performed a patient-level simulation with different utilities. In a particular manner, these microsimulations could partially reflect worse health states due to comorbidities. Another limitation is the uncertainty of the inputs. Although the clinical data were drawn from good quality meta-analyses, the absence of utility and disutility data in our country could over-or underestimate the QALYs. Additionally, using uniform distribution to model costs does not represent the best option for this type of data. Finally, our model did not consider LA's learning curve and its impact on costs, post-surgical complications, or conversion to OA. The model also did not value capital costs (i.e., fiber optics, monitors) or some of the supplies needed to perform LA. Published studies show that these factors can increase costs and, therefore, could decrease this surgical approach's efficiency $[59,60]$.

Several issues remain to be clarified. The first one is about the probability of recurrence after five years and the impact on the quality of life and costs. On the other hand, it is mandatory quantifying the alternatives' efficiency in populations with high surgical risk or difficulty (e.g., obesity, pulmonary diseases). We consider it necessary for future research to obtain data on NOM in developing countries. These data include the clinical effectiveness of other cheaper antibiotic schemes, the estimated risk of recurrence in patients undergoing NOM, the risk of complicated appendicitis, and the probability of performing NOM in settings with a shortage of surgeons. Finally, it is necessary to incorporate into the new evaluations the effect on the costs of the LA learning curve's efficiency.

\section{Conclusions}

LA is a cost-effectiveness alternative in the management of patients with uncomplicated AA. Besides, LA has a high probability of producing more significant monetary benefits than NOM and OA from the payer's perspective in the Colombian health system.

\section{Abbreviations}

AA: Acute appendicitis; OA: Open appendectomy; LA: Laparoscopic appendectomy; NOM: Nonoperative management; QALYs: Quality-adjusted life years; ICER: Incremental cost-effectiveness ratio; NMB: Net monetary benefit.

\section{Supplementary Information}

The online version contains supplementary material available at https://doi. org/10.1186/s12962-021-00288-2.

Additional file 1: Table S1. External validation of the model. This file shows the critical parameter used in the external validation.

Additional file 2: Table S2. Resources used. This file shows the resources, quantities, and values used to calculate the cost in the model.

Additional file 3: Table S3. Probabilities and utilities. This file shows the probabilities and utilities used in the model.

Additional file 4: Table S4. Distributions for PSA. This file shows the distributions and their parameter used in probabilistic sensitivity analysis.

Additional file 5. This file shows the histograms for the outputs of the model. 


\section{Acknowledgements}

We thank to Doctor Alberto García, for his revision of the model structure.

\section{Authors' contributions}

Concept and design: CAG-C, MPR-M. Acquisition of data: CAG-C, EP-R, MPR-M. Analysis and interpretation of data: CAG-C, MPR-M. Drafting of the manuscript: CAG-C, EP-R, MPR-M. Critical revision of the paper for important intellectual content: CAG-C, EP-R, MPR-M. Statistical analysis: CAG-C, EP-R, MPR-M. Provision of study materials or patients: CAG-C, EP-R. Administrative, technical, or logistic support: CAG-C, EP-R. Supervision: CAG-C, EP-R. All authors read and approved the final manuscript.

\section{Funding}

This research did not receive any financial support.

\section{Availability of data and materials}

All data generated or analyzed during this study are included in this published article.

\section{Declarations}

\section{Ethics approval and consent to participate}

Not applicable.

\section{Consent for publication}

Not applicable.

\section{Competing interests}

The authors declare that they have no competing interests.

Received: 3 March 2021 Accepted: 1 June 2021

Published online: 10 June 2021

\section{References}

1. Poon SHT, Lee JWY, Ka Man NG, Chiu GWY, Wong BYK, Foo CC, et al. The current management of acute uncomplicated appendicitis: should there be a change in paradigm? A systematic review of the literatures and analysis of treatment performance. World J Emerg Surg. 2017;12(1):1-10.

2. Buitrago G, Junca E, Eslava-Schmalbach J, Caycedo R, Pinillos P, Leal LC. Clinical outcomes and healthcare costs associated with laparoscopic appendectomy in a middle-income country with universal health coverage. World J Surg. 2019;43(1):67-74. https://doi.org/10.1007/ s00268-018-4777-5.

3. Sippola S, Grönroos J, Tuominen R, Paajanen H, Rautio T, Nordström P, et al. Economic evaluation of antibiotic therapy versus appendicectomy for the treatment of uncomplicated acute appendicitis from the APPAC randomized clinical trial. Br J Surg. 2017;104(10):1355-61.

4. Sugiura K, Suzuki K, Umeyama T, Omagari K, Hashimoto T, Tamura A Cost-effectiveness analysis of initial nonoperative management versus emergency laparoscopic appendectomy for acute complicated appendicitis. BMC Health Serv Res. 2020;20(1):1019.

5. Ruiz-Patiño A, Rey S, Molina G, Dominguez LC, Rugeles S. Cost-effectiveness of laparoscopic versus open appendectomy in developing nations: a Colombian analysis. J Surg Res. 2018:224:33-7.

6. Di Saverio S, Podda M, De Simone B, Ceresoli M, Augustin G, Gori A, et al. Diagnosis and treatment of acute appendicitis: 2020 update of the WSES Jerusalem guidelines. World J Emerg Surg. 2020;15(1):27.

7. Perez N, Romero M. Infección del sitio operatorio de apendicectomías 2009. Rev Colomb Cir. 2009;24:23-30.

8. Choy I, Kitto S, Adu-Aryee N, Okrainec A. Barriers to the uptake of laparoscopic surgery in a lower-middle-income country. Surg Endosc. 2013;27(11):4009-15.

9. Imran JB, Ochoa-Hernandez A, Herrejon J, Ortiz C, Mijangos B, Madni T, et al. Barriers to adoption of laparoscopic cholecystectomy in a county hospital in Guatemala. Surg Endosc. 2019:33(12):4128-32.
10. Sartelli M, Baiocchi GL, Di Saverio S, Ferrara F, Labricciosa FM, Ansaloni L, et al. Prospective observational study on acute appendicitis worldwide (POSAW). World J Emerg Surg. 2018;13:19.

11. Salminen P, Paajanen H, Rautio T, Nordström P, Aarnio M, Rantanen T, et al. Antibiotic therapy vs appendectomy for treatment of uncomplicated acute appendicitis: the APPAC randomized clinical trial. JAMA 2015:313(23):2340-8

12. Park HC, Kim MJ, Lee BH. Randomized clinical trial of antibiotic therapy for uncomplicated appendicitis. Br J Surg. 2017;104(13):1785-90.

13. Salminen $P$, Tuominen $R$, Paajanen $H$, Rautio T, Nordström $P$, Aarnio $M$, et al. Five-year follow-up of antibiotic therapy for uncomplicated acute appendicitis in the APPAC randomized clinical trial. JAMA. 2018;320(12):1259-65.

14. Gkegkes ID, Minis EE, lavazzo C. Effect of caffeine intake on postoperative ileus: a systematic review and meta-analysis. Dig Surg. 2020;37(1):22-31.

15. Jaschinski T, Mosch C, Eikermann M, Neugebauer EAM. Laparoscopic versus open appendectomy in patients with suspected appendicitis: a systematic review of meta-analyses of randomised controlled trials. BMC Gastroenterol. 2015;15:48.

16. Abongwa HK, Cervellin G, Tarasconi A, Perrone G, Baiocchi G, Portolani $\mathrm{N}$, et al. Antibiotics alone for uncomplicated acute appendicitis in high operative risk adult patients: analytical review of RCTs and proposal of evidence based treatment decision. Acta Biomed. 2016;87(3):334-46.

17. Markides G, Subar D, Riyad K. Laparoscopic versus open appendectomy in adults with complicated appendicitis: systematic review and metaanalysis. World J Surg. 2010;34(9):2026-40.

18. Ohtani H, Tamamori Y, Arimoto Y, Nishiguchi Y, Maeda K, Hirakawa K. Meta-analysis of the results of randomized controlled trials that compared laparoscopic and open surgery for acute appendicitis. J Gastrointest Surg Off J Soc Surg Aliment Tract. 2012;16(10):1929-39.

19. Talan DA, Krishnadasan A, R. A, K. P, A. M, G.J. M, et al. Antibiotics-first versus surgery for appendicitis: a US pilot randomized controlled trial allowing outpatient antibiotic management. Ann Emerg Med. 2017;70(1):1-11. e9.

20. Ukai T, Shikata S, Takeda H, Dawes L, Noguchi Y, Nakayama T, Takemura YC. Evidence of surgical outcomes fluctuates over time: results from a cumulative meta-analysis of laparoscopic versus open appendectomy for acute appendicitis. BMC Gastroenterol. 2016;16:37.

21. Wang D, Dong T, Shao Y, Gu T, Xu Y, Jiang Y. Laparoscopy versus open appendectomy for elderly patients, a meta-analysis and systematic review. BMC Surg. 2019;19(1):54.

22. Podda M, Gerardi C, Cillara N, Fearnhead N, Gomes CA, Birindelli A, et al. Antibiotic treatment and appendectomy for uncomplicated acute appendicitis in adults and children: a systematic review and meta-analysis. Ann Surg. 2019;270(6):1028-40.

23. Wu JX, Dawes AJ, Sacks GD, Brunicardi FC, Keeler EB. Cost effectiveness of nonoperative management versus laparoscopic appendectomy for acute uncomplicated appendicitis. Surgery. 2015;158(3):712-21.

24. Haas L, Stargardt T, Schreyoegg J. Cost-effectiveness of open versus laparoscopic appendectomy: a multilevel approach with propensity score matching. Eur J Heal Econ HEPAC Heal Econ Prev Care. 2012;13(5):549-60.

25. Weber SA, Valencia R, Salvador Rodríguez DM, Cueto GJ. Análisis del costo entre apendicectomía abierta versus laparoscópica. An méd Asoc Méd Hosp ABC. 1997;42(2).

26. Gutierrez C, Gómez-Parra N. EL SISTEMA DE SALUD COLOMBIANO EN LAS PRÓXIMAS DÉCADAS : cómo avanzar hacia la sostenibilidad y la calidad en la atención [Internet]. Cuadernos Fedesarrollo. Bogotá; 2018. Available from: https://www.fedesarrollo.org.co/sites/default/files/archivosciadern os/CDF_No_60_Marzo_2018.pdf.

27. Ministerio de Salud y Protección Social. Marco Conceptual de Análisis de los Sistemas de Salud. Proyecto Evaluación y Reestructuración de los Procesos, Estrategias y Organismos Públicos y Privados encargados de adelantar las Funciones de Vigilancia y Control del Sistema de Salud. 2002. https://www.minsalud.gov.co/salud/Documents/MarcoConceptual deAnálisisdelosSistemasdeSalud-CAP1.pdf.

28. IETS Instituto de Evaluación Tecnológica en Salud. Guidelines for the economic evaluation of healthcare technologies in Colombia: technical support documents. 2014. www.iets.org.co. Accessed 15 Dec 2020.

29. Schumm MA, Childers CP, Wu JX, Zanocco KA. Cost saving of short hospitalization nonoperative management for acute uncomplicated appendicitis. J Surg Res. 2020;255:77-85. 
30. Newhall K, Albright B, Tosteson A, Ozanne E, Trus T, Goodney PP. Costeffectiveness of prophylactic appendectomy: a Markov model. Surg Endosc. 2017:31(9):3596-604.

31. Quah GS, Eslick GD, Cox MR. Laparoscopic appendicectomy is superior to open surgery for complicated appendicitis. Surg Endosc 2019;33(7):2072-82.

32. Quartey B. Interval appendectomy in adults: a necessary evil? J Emerg Trauma Shock. 2012;5(3):213-6.

33. Peltrini R, Cantoni V, Green R, Lionetti R, D'Ambra M, Bartolini C, et al. Risk of appendiceal neoplasm after interval appendectomy for complicated appendicitis: a systematic review and meta-analysis. Surgeon. 2021. https://doi.org/10.1016/j.surge.2021.01.010.

34. Kasagi Y, Natsugoe K, Aoyagi T, Nobutou Y, Tsujita E, Ishida M, et al. Validating the efficacy of interval appendectomy for acute appendicitis: representative three cases with different etiologies. Surg Case Rep. 2020;6(1):207

35. Quah GS, Eslick GD, Cox MR. Laparoscopic appendicectomy is superior to open surgery for complicated appendicitis. Surg Endosc. 2019. https:// doi.org/10.1007/s00464-019-06746-6.

36. Talan DA, Saltzman DJ, DeUgarte DA, Moran GJ. Methods of conservative antibiotic treatment of acute uncomplicated appendicitis: a systematic review. J Trauma Acute Care Surg. 2019;86(4):722-36.

37. Instituto de Seguros Sociales. Tarifario ISS. 2001. www.hrd.gov.co/docum entos/facturacion/MANUALDEFACTURACION2013/TARIFASISS-01C256. pdf tarifarioiss. Accessed 4 Feb 2021.

38. Ministerio de Salud de Colombia. Consulta Pública de Precios de Medicamentos en la Cadena de Comercialización - Circular 2 de 2012 [Internet]. https://web.sispro.gov.co/WebPublico/Consultas/ConsultarCNPMCa denaComercializacionCircu2yPA_028_2_2.aspx. Accessed 2 Jan 2021.

39. Colombia $B$ de la $R$ de. Tasa de cambio para rango de fechas dado. https://totoro.banrep.gov.co/analytics/saw.dll?Go\&Action=prompt\& Path=\%2Fshared\%2FSeriesEstadísticas_T\%2F1.TasadeCambioPesoColo mbiano\%2F1.1TRM-Disponible desdeel27denoviembrede1991\%2F1.1.2 .TCM_Pararangodefechasdado\&Options=rdf\&lang $=$ es. Accessed 8 Apr 2021.

40. Tufts Medical Center. Search the CEA Registry. http://healtheconomics dev.tuftsmedicalcenter.org/cear2/search/search.aspx. Accessed 2 Feb 2021

41. Li X, Zhang J, Sang L, Zhang W, Chu Z, Li X, et al. Laparoscopic versus conventional appendectomy — a meta-analysis of randomized controlled trials. BMC Gastroenterol. 2010;10:129.

42. Podda M, Poillucci G, Pacella D, Mortola L, Canfora A, Aresu S, et al. Appendectomy versus conservative treatment with antibiotics for patients with uncomplicated acute appendicitis: a propensity scorematched analysis of patient-centered outcomes (the ACTUAA prospective multicenter trial). Int J Colorectal Dis. 2021. https://doi.org/10.1007/ s00384-021-03843-8.

43. Poprom N, Numthavaj P, Wilasrusmee C, Rattanasiri S, Attia J, McEvoy M, et al. The efficacy of antibiotic treatment versus surgical treatment of uncomplicated acute appendicitis: systematic review and network metaanalysis of randomized controlled trial. Am J Surg. 2019;218(1):192-200.

44. Miyo M, Urabe S, Hyuga S, Nakagawa T, Michiura T, Hayashi N, et al. Clinical outcomes of single-site laparoscopic interval appendectomy for severe complicated appendicitis: comparison to conventional emergency appendectomy. Ann Gastroenterol Surg. 2019;3(5):561-7.

45. Young KA, Neuhaus NM, Fluck M, Blansfield JA, Hunsinger MA, Shabahang $\mathrm{MM}$, et al. Outcomes of complicated appendicitis: is conservative management as smooth as it seems? Am J Surg. 2018;215(4):586-92.
46. Nimmagadda N, Matsushima K, Piccinini A, Park C, Strumwasser A, Lam L, et al. Complicated appendicitis: immediate operation or trial of nonoperative management? Am J Surg. 2019;217(4):713-7.

47. Wang V, Kriger D, Fanous E, Lee A, Zakhary B, Coimbra R, et al. Should all complicated appendicitis be treated the same? The answer is no. Am Surg. 2019;85(10):1179-83.

48. York Health Economics Consortium. Net monetary benefit-YHEC - York Health Economics Consortium. https://yhec.co.uk/glossary/net-monet ary-benefit/. Accessed 4 Feb 2021.

49. World Health Organization. WHO guide to cost-effectiveness analysis. https://www.who.int/choice/publications/p_2003_generalised_cea.pdf. Accessed 9 Apr 2021.

50. McDougall JA, Furnback WE, Wang BCM, Mahlich J. Understanding the global measurement of willingness to pay in health. J Mark Access Health policy. 2020;8(1):1717030.

51. Biondi A, Di Stefano C, Ferrara F, Bellia A, Vacante M, Piazza L. Laparoscopic versus open appendectomy: a retrospective cohort study assessing outcomes and cost-effectiveness. World J Emerg Surg. 2016;11(1):44.

52. BankW. Current health expenditure per capita, PPP (current international \$)_Colombia | Data. https://datos.bancomundial.org/indicator/SH.XPD. CHEX.PP.CD?locations=CO\&most_recent_year_desc $=$ true. Accessed 28 Jan 2021.

53. Minutolo V, Licciardello A, Di Stefano B, Arena M, Arena G, Antonacci V. Outcomes and cost analysis of laparoscopic versus open appendectomy for treatment of acute appendicitis: 4-years experience in a district hospital. BMC Surg. 2014;14:14.

54. Sceats LA, Ku S, Coughran A, Barnes B, Grimm E, Muffly M, et al. Operative versus nonoperative management of appendicitis: a long-term cost effectiveness analysis. MDM Policy Pract. 2019;4(2):2381468319866448.

55. BankW. Current health expenditure per capita, PPP (current international \$) - Colombia | Data.

56. Koumarelas K, Theodoropoulos GE, Spyropoulos BG, Bramis K, Manouras A, Zografos $G$. A prospective longitudinal evaluation and affecting factors of health related quality of life after appendectomy. Int J Surg. 2014;12(8):848-57.

57. Kraemer M, Franke C, Ohmann C, Yang Q. Acute appendicitis in late adulthood: incidence, presentation, and outcome. Results of a prospective multicenter acute abdominal pain study and a review of the literature. Langenbeck's Arch Surg. 2000;385(7):470-81.

58. Golz RA, Flum DR, Sanchez SE, Liu X, Donovan C, Drake FT. Geographic association between incidence of acute appendicitis and socioeconomic status. JAMA Surg. 2020;155(4):330-8.

59. DeMare AM, Luehmann NC, Kawak S, Abbott EE, Long J, Akay B, et al. Cost-effective approach to the laparoscopic appendectomy : balancing disposable instrument cost with operative time. Am Surg. 2020;86(6):715-20.

60. Malhotra L, Pontarelli EM, Grinberg GG, Isaacs RS, Morris JP, Yenumula PR. Cost analysis of laparoscopic appendectomy in a large integrated healthcare system. Surg Endosc. 2021. https://doi.org/10.1007/ s00464-021-08356-7.

\section{Publisher's Note}

Springer Nature remains neutral with regard to jurisdictional claims in published maps and institutional affiliations. 